\title{
The Use of Residual Dipolar Coupling for Conformational Analysis of Structurally Related Natural Products
}

\author{
Christopher S. Lancefield, Alexandra M. Z. Slawin, Nicholas J. Westwood* and Tomas \\ Lebl $^{*[a]}$ \\ C. S. Lancefield, Prof. Dr. N. J. Wetwood, Prof. Dr. A. M. Z. Slawin and Dr. T. Lebl \\ School of Chemistry and Biomedical Sciences Research Complex \\ University of St Andrews and EaStCHEM, North Haugh, St Andrews \\ KY16 9ST (UK) \\ Fax: (+)441334 462595 \\ E-mail:njw3@st-andrews.ac.uk, tl12@st-andrews.ac.uk
}

\begin{abstract}
Determining the conformational preferences of molecules in solution remains a considerable challenge. Recently, the use of residual dipolar coupling (RDC) analysis has emerged as a key method to address this. Whilst to date the majority of the applications have focused on biomolecules including proteins and DNA, the use of RDCs for studying small molecules is gaining popularity. Having said that, the method continues to develop and here we describe an early case study of the quantification of conformer populations in small molecules using RDC analysis. Having been inspired to study conformational preferences by unexpected differences in the NMR spectra and the reactivity of related natural products, we showed that the use of more established techniques was unsatisfactory in explaining the experimental observations. The use of RDCs provided an improved understanding which, following use of methods to quantify conformer populations using RDCs, culminated in a rationalisation of the contrasting diastereoselectivities observed in a ketone reduction reaction.
\end{abstract}

Keywords: NMR; ${ }^{1} \mathrm{H}$; ${ }^{13} \mathrm{C}$; residual dipolar couplings; natural products; solution conformations; conformational analysis, melohenine

\section{Introduction}

X-ray crystallography and NMR spectroscopy remain the two main techniques of choice to investigate the configuration and conformation of natural products. Whilst assigning the absolute configuration of a molecule is clearly essential, often less attention is paid to conformational preferences. Key areas where detailed conformational analysis are important 
include medicinal chemistry as bioactive compounds typically bind their protein targets in a preferred conformation ${ }^{[1]}$. In addition, conformational analysis is also frequently used in helping to explain the observed outcome of a stereoselective reaction. ${ }^{[2]}$ Whilst X-ray crystallography provides definitive information about the 3-dimensional structure of a molecule, including the absolute configuration (in cases where either a "heavy" atom is present or crystals are of exceptional quality), the conformation adopted by a molecule in the solid state can be constrained by crystal lattice forces and intermolecular hydrogen bonding and therefore does not necessarily correspond to the preferred conformation in solution. On the other hand, analysis using classical NMR parameters, such as NOEs and scalar couplings, provides only localised structural information and therefore can fail if the molecule is flexible or if the stereocenters are remote in the bonding network. ${ }^{[3]}$ A recent advance in the NMR analysis of preferred solution conformations has been the use of residual dipolar couplings (RDCs). This anisotropic parameter has been known for a few decades ${ }^{[4]}$ and extensively employed as an additional restraint in the analysis of biomacromolecules since $1997 .{ }^{[5]}$ Later on, the introduction of alignment media compatible with organic solvents enabled researchers to utilise RDCs for the configurational and conformational analysis of small molecules. ${ }^{[6]}$ Nevertheless, the flexibility of molecules ${ }^{[7]}$ or the lack of usable independent RDCs values ${ }^{[8]}$ usually hampers routine applications of this method and therefore further development is still required.

Here we present a NMR conformational analysis case study on members of the melohenine family of natural products (Figure 1) using RDCs. This family of natural products is particularly interesting in this context as they contain a nine-membered ring, the conformation of which is likely to play an important role in their known biological activity. This study was enabled by our recently reported synthesis of $\mathbf{1}$ and $\mathbf{2}^{[9]}$ and inspired by the considerable differences observed following the ${ }^{1} \mathrm{H}$ NMR analysis of authentic samples of these natural products. We show that RDC analysis combined with molecular modelling can provide a very detailed view of the structure of these natural products in solution, which can contrast significantly with the corresponding data obtained by X-ray crystallographic analysis. This study also provides an early example of the use of RDCs to quantify conformational populations. The results of this analysis enabled a possible rationalisation of the contrasting diastereoselectivities observed in the reduction of the ketone groups present in $\mathbf{2}$ and $\mathbf{3}$ to be developed. 


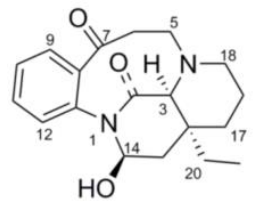

1

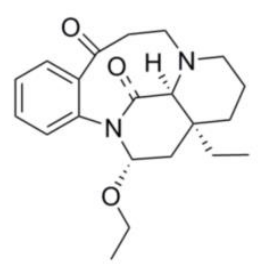

2

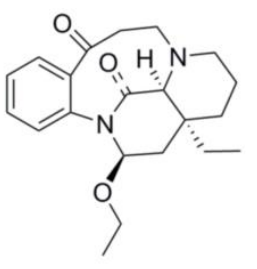

3

Figure 1. Structures of 1, 2 and 3

\section{Results and Discussion}

\section{Synthesis and Reactivity of Melohenines 1-3}

Melohenines $\mathbf{1}$ and $\mathbf{2}$ were prepared as described in our previous report. ${ }^{[9]}$ Preparation of $\mathbf{3}$ was accomplished in two steps from a mixure of eburnamine (4) and isoeburnamine (5) (Scheme 1). ${ }^{[10]} \mathrm{X}$-ray crystallographic analysis of $\mathbf{3}$ was carried out to enable comparison with our previous analysis of $\mathbf{1}$ and $\mathbf{2}$ using this technique. ${ }^{[9]}$

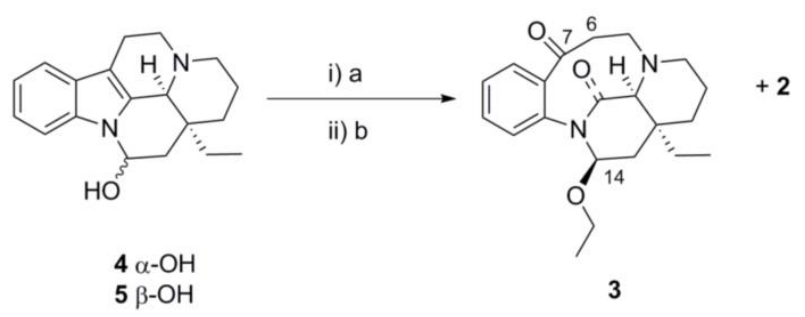

Scheme 1. The synthetic route used to prepare 3: a) $\mathrm{EtOH} / \mathrm{HCl}$; b) methylene blue, air, visible light, EtOH, 18\% isolated yield of $\mathbf{3}$ over the two steps. For details of the X-ray crystallographic analysis of $\mathbf{3}$ see CCDC 1029503.

We initially became interested in the conformational behaviour of $\mathbf{1}, \mathbf{2}$ and $\mathbf{3}$ in solution following comparison of their ${ }^{1} \mathrm{H}$ NMR spectra (Figure 2). Given the very similar geometries adopted by 1, 2 and 3 in the solid phase (Figure 3), it seemed likely that their ${ }^{1} \mathrm{H}$ NMR spectra should be reasonably similar. However, several differences were apparent that warranted further investigation. 


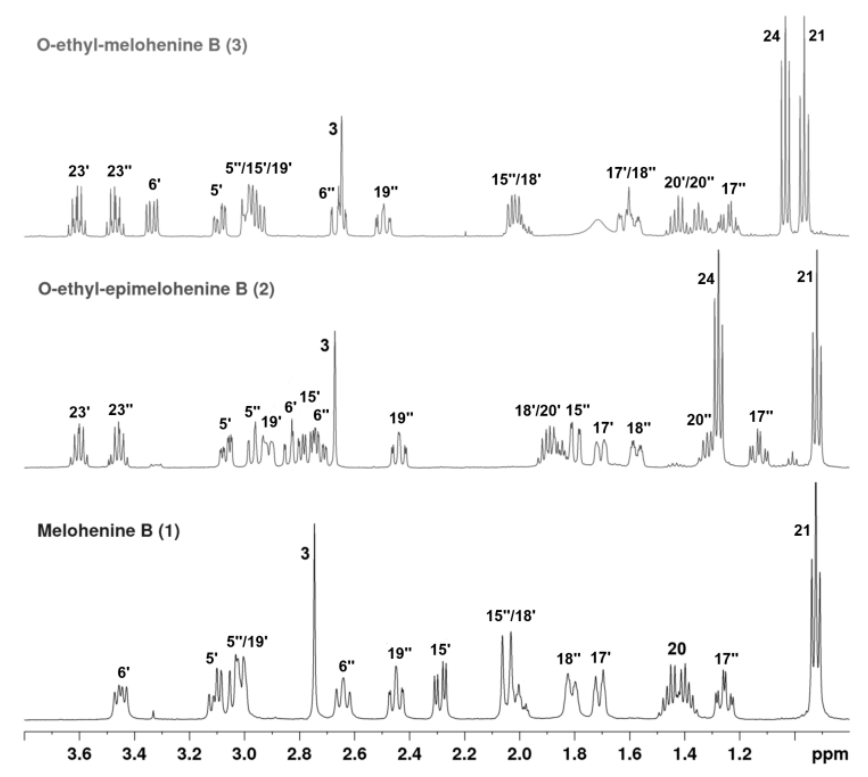

Figure 2. A comparison of a selected region of the ${ }^{1} \mathrm{H}$ NMR of spectra of the natural products 1 and 2 with the structurally related derivative 3 in $\mathrm{CDCl}_{3}$ (see Figures $\mathrm{S} 1-\mathrm{S} 3$ for full spectra). Key differences between the signals corresponding to the C6 methylene protons in 1 and $\mathbf{3}$ and the analogous signals in $\mathbf{2}$ were seen.

In particular, there were considerable differences in the chemical shifts of the signals corresponding to the $\mathrm{C} 6$ methylene protons in $\mathbf{1}$ and $\mathbf{3}$ with respect to the analogous signals in 2. It should be noted that C6 is relatively remote from the $\mathrm{C} 14$ stereocentre that represents the difference between compounds $\mathbf{2}$ and $\mathbf{3}$ (see Figure 1 for numbering). We postulated that this may be due to conformational differences in solution, particularly in the positioning of the $\mathrm{C} 7$ carbonyl functional group.

Any expected conformational variability in the region of the $\mathrm{C} 7$ carbonyl group across the three molecules might also be expected to translate into differences in the reactivity of this group. The reduction of the $\mathrm{C} 7$ ketone in $\mathbf{2}$ and $\mathbf{3}$ to the corresponding benzylic alcohols was therefore investigated. ${ }^{[11]}$ Both $\mathbf{2}$ and $\mathbf{3}$ reacted readily with lithium tri-tert-butoxyaluminium hydride in THF at room temperature (Scheme 2). Reduction of $\mathbf{2}$ gave a mixture of diastereomeric benzylic alcohols 6 and 7 in excellent overall yield $(95 \%$, ratio of $6: 7=4.4: 1$ based on analysis of the ${ }^{1} \mathrm{H}$ NMR spectrum of the crude reaction mixture). The structure of the major diastereomer $\mathbf{6}$ was assigned based on NOE and single crystal X-ray analysis (Figures S4, S9 and Scheme 2). In contrast, reduction of 3 gave exclusively a single diastereomer $\mathbf{8}$ in excellent yield (96\% isolated yield). The structure of $\mathbf{8}$ was assigned based 
on NOE analysis of the enamine $\mathbf{9}$ derived from $\mathbf{8}$ following reaction with trifluoroacetic acid (Figure S5) or on standing in $\mathrm{CDCl}_{3}$.

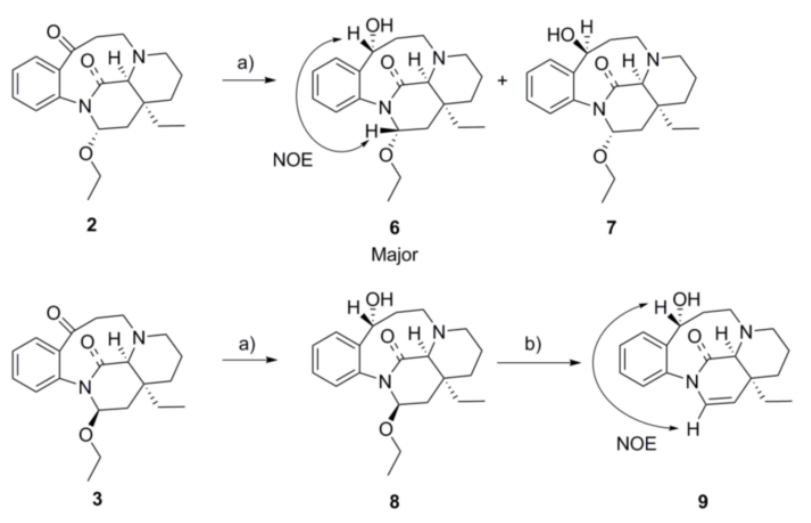

Scheme 2. Reduction of the C7 carbonyl functional group in $\mathbf{2}$ and $\mathbf{3}$ using $\mathrm{LiAlH}\left({ }^{t} \mathrm{BuO}\right)_{3}$, THF, $0{ }^{\circ} \mathrm{C}$ to RT: a) with 2 a mixture of diastereomers $6+7$ was formed in $95 \%$ isolated yield (ratio of 6:7 = 4.4:1 based on ${ }^{1} \mathrm{H}$ NMR analysis of the crude reaction mixture); b) with 3 a single diastereomer $\mathbf{8}$ was found in $96 \%$ yeild; b) $20 \%$ TFA in $\mathrm{CDCl}_{3}, 80 \%$. For details of the X-ray crystallographic analysis of 6 see CCDC 1029504 and Figure S9.

Given both the observed differences in the ${ }^{1} \mathrm{H}$ NMR spectra of $\mathbf{1 - 3}$ and the constrasting degree of diastereoselectivity observed on reduction of the C7 carbonyl group in $\mathbf{2}$ and $\mathbf{3}$, it was decided to carry out a detailed conformational analysis of 1, 2 and 3.

\section{Comparison of the X-ray Crystallographic and Calculated Structures of 1-3}

Compounds 1, 2 and 3 contain one aromatic and three aliphatic rings and therefore would be expected to show some degree of conformational flexibility which might be restricted due to the fusion of the rings. The conformational space of $\mathbf{1 , 2}$ and $\mathbf{3}$ was initialy explored by a Monte Carlo MMFF conformational search. After discarding all high energy side chain conformations it was revealed that each aliphatic ring could realistically adopt only 2 conformations (Figure 3). In the case of the 9-membered ring, the two conformations have the two carbonyl groups in either a syn (s) or an anti (a) orientation. As expected for the two 6-membered (lactam and piperidine) rings, the computational studies predicted that both the chair (c) and the boat (b) conformations were accessible. This analysis suggested that a total of $2^{3}=8$ possible conformations were likely to be adopted by each of $\mathbf{1 - 3}$. A low level theory refinement using a semi-empirical RM1 method ${ }^{[12]}$ led to conformers with high relative energies being discarded (for 1: conformations 1-scb, 1-acc, 1-abb, 1-acb were discarded; for 2: 2-sbb, 2scb, 2-abb, 2-acb; and for 3: 3-sbc, 3-abc, 3-abb, 3acb). Therefore only four 
conformers for each compound were refined at the B3LYP/6-31G** level of theory and considered in the analysis that followed (Table S1, S9-S11).
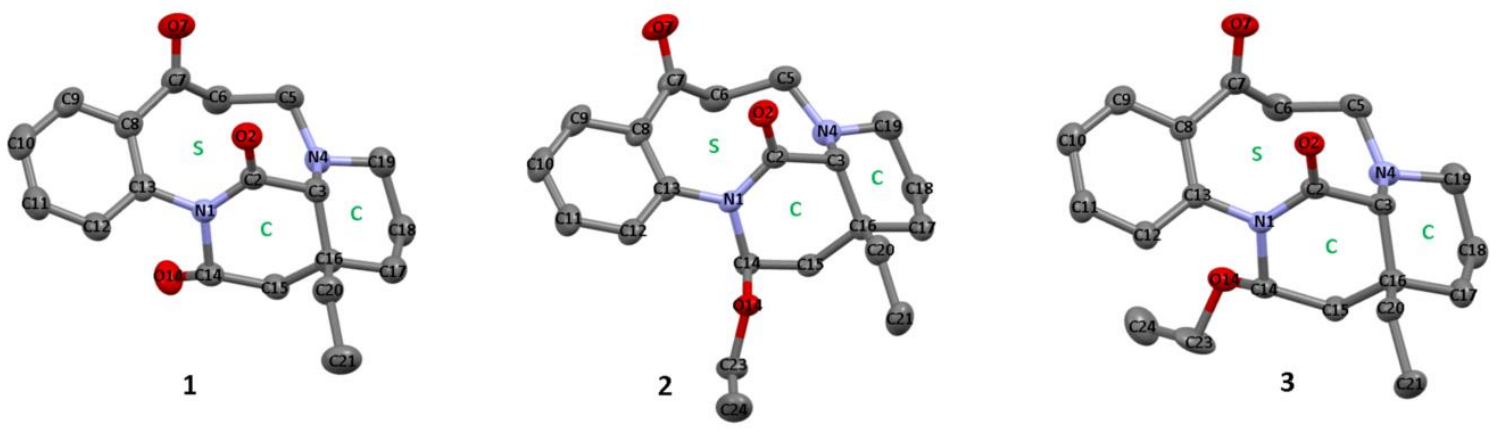

Figure 3. Representations of the X-ray crystal structures of 1, 2 and 3 showing that all three molecules adopt a conformation in the solid state that has the two carbonyl groups in a syn orientation in the 9-membered ring. Both of the six-membered rings adopt a chair conformation. This conformation is referred to here as the scc conformer as the 9-membered ring adopts a syn (s), the lactam ring a chair (c) and the piperidine ring a chair (c) conformation. This nomenclature is used throughout.

Selected torsion angles taken from the X-ray crystal structures of 1, 2 and $\mathbf{3}$ (Figure 3) were compared with those calculated using the B3LYP/6-31G** level of theory (Table 1). All three molecules 1-3 adopt the scc conformation in the solid state despite the differences in the $\mathrm{C} 14$ configuration and the $O$-substituent at the $\mathrm{C} 14$ position. There was very good agreement between the calculated and experimentally determined structures for the scc geometry of 2 (2-scc). On the other hand, rather larger discrepancies were seen for both the 1-scc and 3-scc geometries (Table 1). This is most apparent for the C2-N1-C14-C15 ( $\beta$ ) and C2-N1-C14-O14 ( $\delta)$ dihedral angles which showed differences between the experimentally observed and calculated values ranging from 8.6 to $14.3^{\circ}$. Furthermore the 1-scc conformer is predicted by our DFT calculations to be around $15 \mathrm{~kJ} \mathrm{~mol}^{-1}$ higher in energy than the global minimum 1-sbc conformer (Table 1). One possible explanation for this observation is that $\mathbf{1}$ and $\mathbf{3}$ have a constrained geometry in the solid state due to hydrogen bonding and/or crystal packing forces that the computational methods adopted here cannot reproduce. This result also suggested that the preferred conformations adopted by $\mathbf{1}$ and $\mathbf{3}$ upon dissolution may well differ from the observed solid state structures.

\section{RDC-Based Conformational Analysis}


Initial attempts at conformational analysis using ${ }^{1} \mathrm{H}$ chemical shifts, vicinal couplings and NOEs (Table S2 and Figures S6 and S7) were deemed inconclusive because only a limited number of parameters was available. ${ }^{[13]}$ In addition, the observed differences in reactivity of the melohenines could not readily be explained. Therefore it was decided to use residual dipolar couplings (RDCs) to investigate the conformational behaviour of 1-3 further. Unlike NOEs and ${ }^{3} J$ scalar couplings, RDCs provide information about the angular orientation of the different internuclear vectors regardless of their distance and thus there is a higher chance that more conclusive data will be obtained even for structures as complex as the melohenines. ${ }^{[14]}$

Samples of 1, 2 and 3 were oriented in a lyotropic liquid crystalline matrix of poly-benzyl-Lglutamate (PBLG) ${ }^{[15]}$ and three sets of 8 (for 1), 9 (for 2) and 11 (for 3) ${ }^{1}$ DCH RDC values ranging from - 46 to $43 \mathrm{~Hz}$ were obtained using ${ }^{1} \mathrm{H},{ }^{13} \mathrm{C}$-CLIP-HSQC ${ }^{[16]}$ and ${ }^{1} \mathrm{H},{ }^{13} \mathrm{C}-\mathrm{G}-\mathrm{BIRD}$ HSQC $^{[17]}$ experiments (Tables S4-S6). The experimental RDC data were fitted to each possible conformer using the singular value decomposition (SVD) method as implemented in the program MSpin 1.3. ${ }^{[18]}$ Since there are only $6 \mathrm{CH}$ groups in $\mathbf{1}, \mathbf{2}$ and $\mathbf{3}$, RDCs from the methylene groups had to be used in order to discriminate particular conformers. To avoid the assignment of the individual diastereotopic methylene protons and to decrease the effect of strong coupling on the accuracy, methylene group RDCs were derived initially only from F1-splitting in the ${ }^{1} \mathrm{H},{ }^{13} \mathrm{C}-\mathrm{G}-\mathrm{BIRD}-\mathrm{HSQC}$ experiments and were then included in calculations as the half-sum of the corresponding individual values using the methylene averaging approach implemented in MSpin 1.3 (for aligment tensor computation details see SI page 22 23). ${ }^{[19]}$ The quality factor $Q^{[20]}$ was used to evaluate the agreement between the experimental and back calculated RDCs, where a small $Q$ indicates a good numerical fit. In order to include the impact of measurement errors on the analysis, a Monte Carlo bootstrapping procedure with normalized Gaussian distribution of 256 points and standard deviation of 1.5 $\mathrm{Hz}$ was employed. The resulting mean quality factors $\langle Q\rangle$ and standard deviations (s.d.) are also summarised in Table 2.

The lowest quality factor $\langle Q\rangle$ for $\mathbf{1}, \mathbf{2}$ and $\mathbf{3}$ were obtained for the 1-sbc $(\langle Q\rangle=0.059), \mathbf{2}$-scc $(\langle Q\rangle=0.074)$ and 3-scc $(\langle Q\rangle=0.092)$ conformers respectively (Table 2). This was in agreement with the lowest relative energies calculated at the B3LYP/6-31G** level of theory (Table 1). In the case of $\mathbf{2}$ and $\mathbf{3}$, the rest of the conformers presented significantly higher quality factors $(0.189-0.450)$. It was therefore concluded with confidence that both 2 and 3 
preferentially adopt the same scc conformation in solution and in the solid state. This RDCbased conclusion was also in accordance with the results obtained from the chemical shift, vicinal coupling (Table S2) and NOE analyses (Figure S7 and Table S3).

The relatively high $\langle Q\rangle$ factor (0.184) obtained for the 1-scc conformer implied, in accordance with the previous results presented here, that $\mathbf{1}$ adopts an alternative conformation upon dissolution. Although the 1-sbc conformer has the lowest $\langle Q\rangle$ factor $(0.059 \pm 0.018)$ and relative energy, it was not possible to be certain whether it was the predominant conformer in solution because two other conformers 1-abc and 1-sbb show comparable $\langle Q\rangle$ factors $(0.066$ \pm 0.016 and $0.074 \pm 0.014$, respectively). In order to refine the data set for $\mathbf{1}, \mathrm{RDC}$ for the diastereotopic protons of selected methylene groups were derived from F2-splitting in the ${ }^{1} \mathrm{H},{ }^{13} \mathrm{C}$-CLIP-HSQC and from the F1-splitting in ${ }^{1} \mathrm{H},{ }^{13} \mathrm{C}-\mathrm{G}-\mathrm{BIRD}-\mathrm{HSQC}$ with Multiple Quantum J-evolution (Table S7). ${ }^{[21]}$ As the stereochemical assignment of the $\mathrm{CH}_{2}$ groups was unknown, SVD fitting of all four possible assignment combinations for each conformer of $\mathbf{1}$ was carried out. The Monte Carlo bootstrapping procedure with normalized Gaussian distribution of 256 points and standard deviation of $1.5 \mathrm{~Hz}$ was used in an analogous manner to the previous tensor analysis. The comparison of resulting mean quality factors $\langle Q\rangle$ is shown in Table S8 and Figure 4. The refinement did not have a profound effect on the lowest value $(\langle Q\rangle=0.059 \pm 0.014)$ that was obtained for the 1-sbc conformer having H6' and H17', in the axial positions. This stereochemical assignment is validated by the large axial-axial coupling (14.0 and $13.5 \mathrm{~Hz}$, respectively) seen in the multiplets assigned to these protons. Nevertheless, the analysis became more conclusive since considerably higher $\langle Q\rangle$ values were found for all the remaining candidates. The second lowest $\langle Q\rangle=0.101 \pm 0.009$ resulted from the 1-abc conformer. 


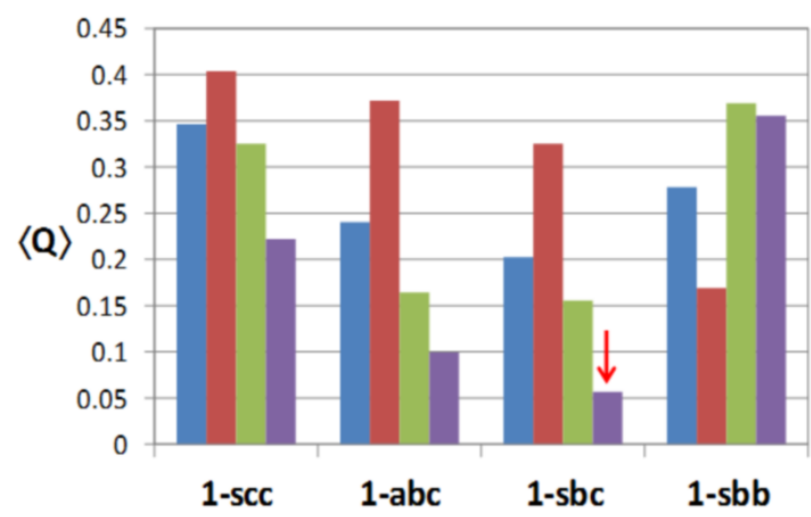

Figure 4. Comparison of mean quality factors $\langle Q\rangle$ for selected conformers of $\mathbf{1}$. The four possible assignments arising from swapping of the methylene protons for each conformer are represented by different colour bars. The red arrow highlights the conformer assignment with the lowest $\langle Q\rangle=0.058 \pm 0.014$ obtained for 1-sbc conformer.

In accordance with the results of traditional conformational analysis, RDC fit to single conformations suggests that 1-sbc, 2-scc and 3-scc are the predominant conformers of 1, 2 and $\mathbf{3}$ in solution. However, the rather small differences between the relative free energies calculated at the B3LYP/6-31G** level of theory (Table 1) do not allow the presence of a conformational equilibrium to be excluded. Furthermore, the existence of equilibrating conformers in solution could also explain that $\langle Q\rangle$ values obtained for 2-scc (0.074) and 3-scc (0.092) conformers are slightly higher than for 1-sbc (0.059) conformer and the differences in reactivity (Scheme 2). Therefore it was decided to analyse the RDC data for 1-3 using the single tensor approximation method as implemented in MSpin 1.3. ${ }^{[18 \mathrm{~b}]}$ For this calculation, the conformations of each compound were aligned into a single axis frame using leastsquares superimposition of aromatic carbon atoms and then conformational populations were fitted to the experimental RDCs by using a combined Levenberg-Marquadt SVD procedure (Table 2). ${ }^{[19 b]}$ In the case of $\mathbf{1}$, no better solution than the single conformer 1-sbc was found. On the other hand, combinations of conformers 2-scc, 2-sbc, 2-acc in the ratio 53:30:17 and 3-scc, 3-scb in the ratio 80:20 showed lower quality factors than the single conformers. As the lowering of the quality factor is rather small, the multi-conformational models were also assessed using Akaike's Information Criterion (AIC) that has already been applied to conformational problems in RDC analysis (Table 3). ${ }^{[19 b, 22]}$ In the case of compound 2, the ensembles of two and three conformers show lower values of the AIC than the single conformer model which implies that mixing of conformations is physically relevant. On the other hand, the values of AIC calculated for 3-scc and 3-scc + 3-scb models (107.8 and 
124.7, respectively) show an opposite trend. Therefore we suppose that the RDC data were overfitted and $\mathbf{3}$ has a rigid scc conformation which is in accordance with the rather large energy gap between the basal and upper conformations calculated for $\mathbf{3}$ (Table 1).

\section{A possible rationalisation of the differences in conformational behaviour and reactivity across the melohenines}

The crystal packing of 1 shows a close intermolecular contact of $2.840 \AA$ between 014 of one molecule of 1 and $\mathrm{O} 2$ of its nearest neighbour (Figure 5A). Therefore we propose that the 1-scc conformation is stabilised over the 1-sbc conformer in the solid state by intermolecular hydrogen bonding which compensates for the fact that the 1-scc conformer is predicted by our DFT calculations to be around $15 \mathrm{~kJ} \mathrm{~mol}^{-1}$ higher in energy than the 1-sbc conformer adopted in solution (Table 1). Furthermore we assume that an intramolecular hydrogen bond is formed between the $\mathrm{C} 14-\mathrm{O} 14 \mathrm{H}$ hydrogen and $\mathrm{N} 4$ which stabilises the 1-sbc conformation in solution (Figure 5B). This proposal correlates with the results of the multiconformational analysis of RDCs suggesting $\mathbf{1}$ exists in solution as a single 1-sbc conformer. Due to the lack of possibility to form an analogous hydrogen bond, ethoxy substituted analogue $\mathbf{3}$ retains in solution the 3-scc conformation. In the case of $\mathbf{2}$, the different C14 configuration likely removes steric hindrance of the ethoxy substituent which likely results in conformational mobility. Therefore $\mathbf{2}$ was found to exist in solution as a mixture of 2-scc, 2-sbc and 2-acc conformers which, we assume, is the reason for the differences in the reactivity of $\mathbf{2}$ and $\mathbf{3}$. The 9-membered ring in $\mathbf{3}$ adopts a conformation with the two carbonyl groups in a syn orientation (3-scc). Inspection of this conformer would suggest that approach of a hydride reducing agent should occur exclusively from the same face resulting in a highly diastereoselective reduction. In contrast, both the syn and anti-conformations of the 9-membered ring for $\mathbf{2}$ are predicted to be accessible by our RDC analysis and this would imply that attack from either face could occur at C7 (Figure 6). Whilst these results generally agree with the calculated conformer populations based on the RDC data, it should be noted that the relative ratios of diastereomers obtained in these experiments does not necessarily reflect the relative conformer populations as the conformers are likely able to equilibrate rapidly under the reaction conditions and so the Curtin-Hammett principle probably applies. $^{[23]}$ 


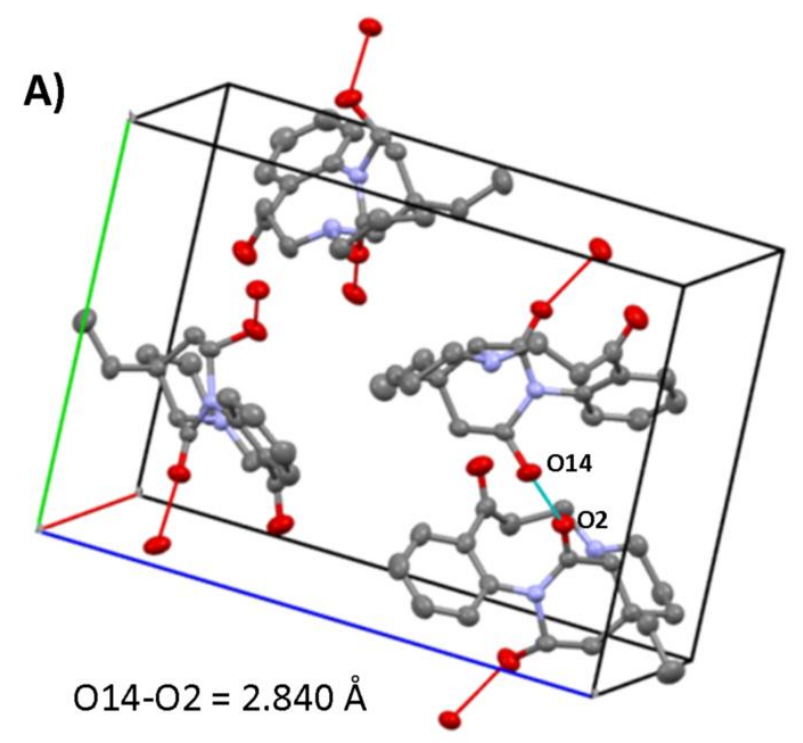

B)

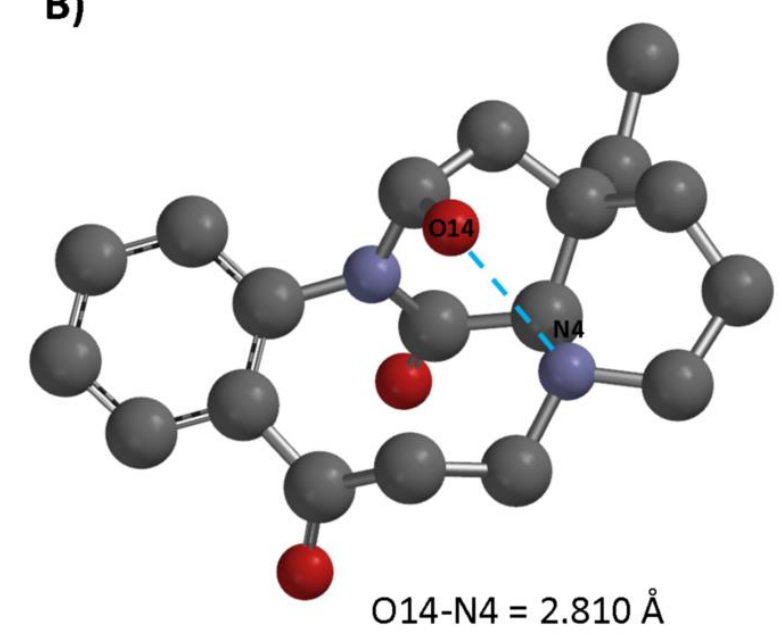

Figure 5. A Crystal packing of 1 showing close intermolecular contacts of $2.840 \AA$ between $\mathrm{O} 14$ and $\mathrm{O} 2$ which likely enables hydrogen bonding and stabilises the 1-scc conformation in the solid state. B Structure of the 1-sbc conformers calculated at the B3LYP/6-31G*. 

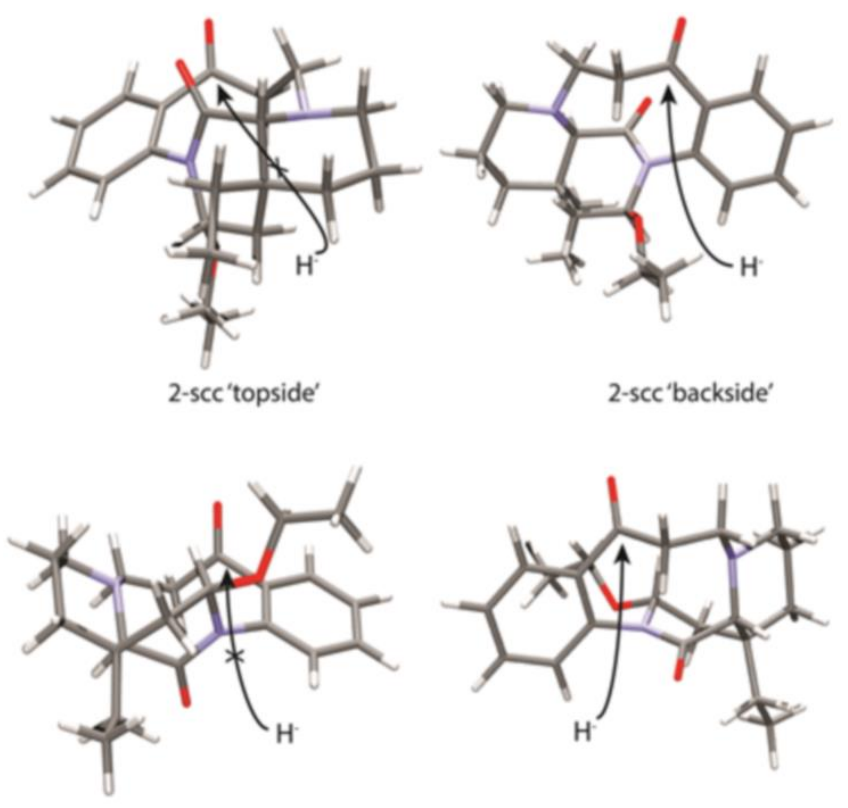

2-abc 'backside'

2-abc'topside'

Figure 6. 3D representation of the 2-scc and 2-abc conformations showing hydride attack is only possible from one face in each conformation. The faces are opposite in each case giving rise to the two observed diastereomers ( 6 and 7$)$.

\section{Conclusion}

This detailed study was initially inspired by the differences observed in the ${ }^{1} \mathrm{H}$ NMR spectra of three members of the melohenine family of natural products 1-3, especially as $\mathbf{1}, \mathbf{2}$ and $\mathbf{3}$ were shown by X-ray crystallography to adopt the same preferred conformation in the solid state. As inconclusive results were obtained using traditional NMR approaches, it was decided to carry out a detailed RDC analysis. Whilst some reports on the use of RDCs to study small flexible molecule in solution exist, this remains a relatively new and underused approach. Our initial RDC analysis provided results that were consistent with the traditional methods we had used. We concluded that $\mathbf{1}$ shows in solution a strong preference for a single 1-sbc conformation that differed from the conformer found in the solid state (1-scc) and also differed from the major conformers adopted by $\mathbf{2}$ and $\mathbf{3}$ in solution (2-scc and 3-scc respectively). This was rationalised based on the likely formation of an intramolecular hydrogen bond between the $\mathrm{O} 14 \mathrm{H}$ hydrogen atom and N4 in 1 in solution. More detailed analysis incorporating the use of SVD single tensor aproximation fitting provided further clarification. It was shown that conformations of $\mathbf{1}$ and $\mathbf{3}$ (1-sbc and 3-scc, respectively) are rather rigid while $\mathbf{2}$ adopts a conformational equilibrium and that knowledge of the preferred 
conformers enabled us to provide a potential rationalisation for the difference in stereochemical outcome exhibited by $\mathbf{2}$ and $\mathbf{3}$ on ketone reduction. We believe that the use of RDCs can contribute significantly to the understanding of conformational equilibrium in complex small molecules as exemplified here with the melohenine family of natural products.

\section{Experimental Section}

\section{General Experimental}

Chemicals and reagents were obtained from commercial suppliers and were used as received unless otherwise stated. All reactions involving moisture sensitive reagents were performed in oven or flame dried glassware under a positive pressure of nitrogen. Tetrahydrofuran (THF) was obtained dry from a solvent purification system (MBraun, SPS-800).

Thin-layer chromatography was performed using glass plates coated with silica gel (with fluorescent indicator $\mathrm{UV}_{254}$ ). Developed plates were air-dried and analysed under a UV lamp or by $\mathrm{KMnO}_{4}$ dip staining. Flash column chromatography was performed using silica gel (40$63 \mu \mathrm{m})$.

Melting points were recorded in open capillaries using an Electrothermal 9100 melting point apparatus. Values are quoted to the nearest $1{ }^{\circ} \mathrm{C}$ and are uncorrected.

Infrared spectra were recorded on a Perkin Elmer Spectrum GX FT-IR spectrometer using either thin films on $\mathrm{NaCl}$ plates $(\mathrm{NaCl})$ or $\mathrm{KBr}$ discs $(\mathrm{KBr})$ as stated. Absorption maxima are reported as wavenumbers $\left(\mathrm{cm}^{-1}\right)$.

Low resolution (LR) and high resolution (HR) electrospray mass spectral (ES-MS) analyses were acquired by electrospray ionisation (ESI), electron impact (EI) or chemical ionisation (CI). These were acquired by the EPSRC National Mass Spectrometry Service or within the School of Chemistry, University of St Andrews.

Nuclear magnetic resonance (NMR) spectra were acquired on either a Bruker Avance 300 $\left({ }^{1} \mathrm{H}, 300.1 \mathrm{MHz} ;{ }^{13} \mathrm{C}, 75.5 \mathrm{MHz}\right)$, Bruker Avance II $400\left({ }^{1} \mathrm{H}, 400.1 \mathrm{MHz} ;{ }^{13} \mathrm{C}, 100.6 \mathrm{MHz}\right)$, Bruker Avance $500\left({ }^{1} \mathrm{H}, 499.9 \mathrm{MHz} ;{ }^{13} \mathrm{C}, 125.7 \mathrm{MHz}\right)$ or Bruker Avance III $500\left({ }^{1} \mathrm{H}, 500.1\right.$ $\left.\mathrm{MHz},{ }^{13} \mathrm{C}, 125.7 \mathrm{MHz}\right)$ spectrometer and in the deuterated solvent stated. All NMR spectra were acquired using the deuterated solvent as the lock. Coupling constants $(J)$ are quoted in $\mathrm{Hz}$ and are recorded to the nearest $0.1 \mathrm{~Hz}$. The following abbreviations are used; s, singlet; $\mathrm{d}$, doublet; dd, doublet of doublets; ddd, doublet of doublets of doublets; dt, doublet of triplets; t, triplet; tdd, triplet of a doublets of a doublets; m, multiplet; q, quartet; qt, quintet; and br, broad. 


\section{Synthesis of 3}

To a solution of a mixture of eburnamine and isoeburnamine ${ }^{[24]}(280 \mathrm{mg}, 0.94 \mathrm{mmol})$ in ethanol $(10 \mathrm{~mL})$ was added, by the dropwise addition, $4 \mathrm{M} \mathrm{HCl}$ in dioxane until the reaction was judged to be complete by TLC analysis. The reaction was quenched by the addition of sat. $\mathrm{NaHCO}_{3}(20 \mathrm{~mL})$ and concentrated in vacuo. The reaction mixture was then partitioned between DCM $\left(10 \mathrm{~cm}^{3}\right)$ and brine $(20 \mathrm{~mL})$ and the aqueous phase extracted with DCM $(2 \mathrm{x}$ $10 \mathrm{~cm}^{3}$ ). The combined organic extracts were dried over anhydrous $\mathrm{K}_{2} \mathrm{CO}_{3}$ and concentrated in vacuo to give a crude mixture of $O$-ethyleburnamine and $O$-ethylisoeburnamine which was taken up in ethanol $(10 \mathrm{~mL})$ and methylene blue $(c a .1 \mathrm{mg})$ was added. The reaction mixture was irradiated with a red LED ( 3 watt, $627 \mathrm{~nm}$ ) in the presence of air for $24 \mathrm{hrs}$. The reaction was then concentrated in vacuo and purified by column chromatography (10\% EtOAc/Hexanes) to yield 3 as a colourless crystalline solid (55 mg, $18 \%$ ); $\mathrm{mp}=159-161{ }^{\circ} \mathrm{C}$; $[\alpha]_{\mathrm{D}}{ }^{20}-144$ (c 1.2, $\mathrm{CHCl}_{3}$ ); for ${ }^{1} \mathrm{H}$ and ${ }^{13} \mathrm{C}$ NMR assignments see Figure S3 below; IR(film): $\mathrm{U}_{\max } \mathrm{cm}^{-1} 2928,2358,1678,1599,1456,1321,1078$; HRMS (ESI, m/z) calcd for $\mathrm{C}_{21} \mathrm{H}_{29} \mathrm{~N}_{2} \mathrm{O}_{3}$ $[\mathrm{M}+\mathrm{H}]^{+}:$357.2178; found: 357.2175

Crystals suitable for single crystal X-ray analysis were obtained from ethanol. See Figure S8 for the Ortep plot of the crystal structure of $\mathbf{3}$.

\section{Reduction of 2 to give a mixture of 6 and 7}

To a solution of $\mathrm{LiAlH}_{4}(1 \mathrm{M}$ in THF, $0.63 \mathrm{~mL}, 5.0 \mathrm{eq})$ in THF $(1 \mathrm{~mL})$ at $0{ }^{\circ} \mathrm{C}$ was added ${ }^{t} \mathrm{BuOH}(0.18 \mathrm{~mL}, 1.9 \mathrm{mmol}, 15 \mathrm{eq})$ dropwise. The mixture was then stirred for ten minutes at room temperature before use. This solution of $\mathrm{LiAlH}\left(\mathrm{O}^{t} \mathrm{Bu}\right)_{3}$ is then added dropwise to a cooled (ice) solution of 2 (45 mg, $0.13 \mathrm{mmol}, 1.0 \mathrm{eq}$ ) in THF (1 mL) and mixture then stirred at room temperature for 1 hour. The reaction was then cooled to $0{ }^{\circ} \mathrm{C}$ and quenched by the dropwise addition of sat. $\mathrm{Na}_{2} \mathrm{SO}_{4}$, filtered and partitioned between ethyl acetate and brine. The aqueous phase was extracted with EtOAc $(2 \times 10 \mathrm{~mL})$ and the combined organic extracts dried over $\mathrm{Na}_{2} \mathrm{SO}_{4}$ and concentrated in vacuo. Purification by column chromatography (10$30 \%$ EtOAc/Hexanes) gave an inseparable mixture of $\mathbf{6}$ and 7 as a colourless solid (43 mg, 95\%). Recrystallisation from $\mathrm{MeOH}$ gave a colourless crystalline solid predominantly consisting of 6.

6 Major : ${ }^{1} \mathrm{H}$ NMR (500 MHz, $\left.\mathrm{CDCl}_{3}\right) \delta 7.57(1 \mathrm{H}, \mathrm{d}, J$ 8.3), $7.45(1 \mathrm{H}, \mathrm{dd}, J$ 7.7, 1.4), 7.37 (1 H, dd, J 7.7, 1.2), 7.30 (1 H, dd, J 7.6, 1.5), 5.49 - 5.43 (1 H, m), 5.03 (1 H, dd, J 5.6, 3.2), 3.39 (1 H, dq, J 9.0, 6.9), 3.14 (1 H, dq, J 9.0, 7.0), $2.87-2.73(2 \mathrm{H}, \mathrm{m}), 2.69-2.57$ (2 H, 
m), $2.52(1 \mathrm{H}, \mathrm{s}), 2.25(2 \mathrm{H}, \mathrm{m}), 1.96-1.85(1 \mathrm{H}, \mathrm{m}), 1.80-1.58(4 \mathrm{H}, \mathrm{m}), 1.42-1.33(1 \mathrm{H}$, m), $1.13\left(1 \mathrm{H}, \mathrm{td}, J\right.$ 13.4, 4.6), $1.05(3 \mathrm{H}, \mathrm{t}, J 7.0), 0.92(3 \mathrm{H}, \mathrm{t}, J 7.4) ;{ }^{13} \mathrm{C} \mathrm{NMR}(126 \mathrm{MHz}$, $\left.\mathrm{CDCl}_{3}\right) \delta 176.5,144.9,137.7,131.4,128.5,127.3,124.5,89.6,74.8,67.1,64.9,56.2,54.6$, 38.8, 35.9, 32.9, 32.4, 32.2, 22.1, 15.5, 7.6; IR(film): $v_{\max } \mathrm{cm}^{-1} 3352,2928,2359,1653,1437$, 1340, 1056; HRMS (ESI, m/z) calcd for $\mathrm{C}_{21} \mathrm{H}_{30} \mathrm{~N}_{2} \mathrm{O}_{4}[\mathrm{M}+\mathrm{H}]^{+}:$359.2335; found: 359.2331; the optical rotation of $\mathbf{6}$ (contaminated with $c a$. $7 \%$ of 7 as judged by ${ }^{1} \mathrm{H}$ NMR) was determined to be $[\alpha]_{\mathrm{D}}{ }^{20}+148\left(\mathrm{c} 0.17, \mathrm{CHCl}_{3}\right)$.

Crystals suitable for single crystal X-ray analysis were obtained from methanol. See Figure S9 for the Ortep plot of the crystal structure of 6.

Further recrystallisation of the solid obtained from the initial mother liquors and subsequent concentration of the mother liquors gave a solid that contained an approximately 1:1 mixture of 6 and 7. From ${ }^{1} \mathrm{H}$ and ${ }^{13} \mathrm{C}$ NMR analysis of this sample it was possible to identify the signals corresponding to 7 .

7 Minor: ${ }^{1} \mathrm{H}$ NMR $\left(500 \mathrm{MHz}, \mathrm{CD}_{2} \mathrm{Cl}_{2}\right) \delta 7.61(\mathrm{dd}, J=7.8,1.6 \mathrm{~Hz}, 1 \mathrm{H}), 7.37-7.26(\mathrm{~m}, 3 \mathrm{H})$, $7.17(\mathrm{dd}, J=7.4,1.7 \mathrm{~Hz}, 1 \mathrm{H}), 4.95(\mathrm{~d}, J=9.8 \mathrm{~Hz}, 1 \mathrm{H}), 4.80-4.71(\mathrm{~m}, 1 \mathrm{H}), 3.51(\mathrm{dq}, J=$ 9.2, $7.0 \mathrm{~Hz}, 1 \mathrm{H}), 3.33(\mathrm{dq}, J=9.2,7.0 \mathrm{~Hz}, 1 \mathrm{H}), 3.05-2.85(\mathrm{~m}, 4 \mathrm{H}), 2.63-2.52(\mathrm{~m}, 2 \mathrm{H})$, $2.49(\mathrm{~s}, 1 \mathrm{H}), 2.32-2.10(\mathrm{~m}, 4 \mathrm{H}), 2.10-1.85(\mathrm{~m}, 5 \mathrm{H}), 1.79-1.54(\mathrm{~m}, 15 \mathrm{H}), 1.21(\mathrm{t}, J=7.0$ $\mathrm{Hz}, 3 \mathrm{H}), 1.16(\mathrm{td}, J=13.0,4.6 \mathrm{~Hz}, 2 \mathrm{H}), 0.99-0.95(\mathrm{~m}, 3 \mathrm{H}) ;{ }^{13} \mathrm{C} \mathrm{NMR}\left(126 \mathrm{MHz}, \mathrm{CDCl}_{3}\right) \delta$ 174.6, 144.1, 140.5, 131.4, 129.4, 128.2, 128.0, 90.5, 75.2, 74.1, 64.0, 56.3, 54.9, 36.9, 32.0, $31.0,29.6,27.5,21.4,15.4,7.3$.

\section{Synthesis of 8}

To a solution of $\mathrm{LiAlH}_{4}(1 \mathrm{M}$ in THF, $0.28 \mathrm{~mL}, 5.0 \mathrm{eq})$ in THF $(1 \mathrm{~mL})$ at $0{ }^{\circ} \mathrm{C}$ was added ${ }^{t} \mathrm{BuOH}(0.080 \mathrm{~mL}, 0.84 \mathrm{mmol}, 15 \mathrm{eq})$ dropwise. The mixture was then stirred for ten minutes at room temperature before use. This solution of $\mathrm{LiAlH}\left(\mathrm{O}^{t} \mathrm{Bu}\right)_{3}$ was then added dropwise to a cooled (ice) solution of $\mathbf{3}(50 \mathrm{mg}, 0.056 \mathrm{mmol}, 1.0 \mathrm{eq})$ in THF (1 mL) and the mixture was stirred at room temperature for 1 hour. The reaction was cooled to $0{ }^{\circ} \mathrm{C}$ and quenched by the dropwise addition of sat. $\mathrm{Na}_{2} \mathrm{SO}_{4}(20 \mathrm{~mL})$. After filtration, the reaction mixture was partitioned between ethyl acetate $(20 \mathrm{~mL})$ and brine $(15 \mathrm{~mL})$. The aqueous phase was extracted with EtOAc $(2 \times 10 \mathrm{~mL})$ and the combined organic extracts dried over anhydrous $\mathrm{Na}_{2} \mathrm{SO}_{4}$ and concentrated in vacuo. Purification by column chromatography (10-30\% EtOAc/Hexanes) gave 8 as a colourless oil (48 mg, 96\%); $[\alpha]_{\mathrm{D}}{ }^{20}+109\left(\mathrm{c} 0.58, \mathrm{CHCl}_{3}\right) ;{ }^{1} \mathrm{H}$ 
$\operatorname{NMR}\left(500 \mathrm{MHz}\right.$, Acetone- $\left.d_{6}\right) \delta 7.60(\mathrm{~d}, J=7.4 \mathrm{~Hz}, 1 \mathrm{H}), 7.35-7.26(\mathrm{~m}, 2 \mathrm{H}), 7.24(\mathrm{t}, J=7.6$ $\mathrm{Hz}, 1 \mathrm{H}), 5.85-5.68(\mathrm{~m}, 1 \mathrm{H}), 5.23-5.11(\mathrm{~m}, 1 \mathrm{H}), 4.08(\mathrm{~d}, J=4.9 \mathrm{~Hz}, 1 \mathrm{H}), 3.31(\mathrm{dt}, J=$ $13.8,6.9 \mathrm{~Hz}, 1 \mathrm{H}), 3.05-2.75(\mathrm{~m}, 7 \mathrm{H}), 2.44(\mathrm{dd}, J=12.5,6.1 \mathrm{~Hz}, 1 \mathrm{H}), 2.36-2.23(\mathrm{~m}, 2 \mathrm{H})$, $2.23-2.13(\mathrm{~m}, 1 \mathrm{H}), 2.12-1.97(\mathrm{~m}, 5 \mathrm{H}), 1.85(\mathrm{dd}, J=13.5,6.4 \mathrm{~Hz}, 1 \mathrm{H}), 1.65-1.44(\mathrm{~m}$, $4 \mathrm{H}), 1.40-1.17(\mathrm{~m}, 4 \mathrm{H}), 0.96(\mathrm{t}, J=7.5 \mathrm{~Hz}, 3 \mathrm{H}), 0.73(\mathrm{t}, J=7.0 \mathrm{~Hz}, 3 \mathrm{H}) .{ }^{13} \mathrm{C}$ NMR $(126$ MHz, Acetone- $\left.d_{6}\right) \delta 175.4,150.0,138.0,129.0,128.2,127.0,125.4,90.2,75.2,67.5,66.8$, 58.0, 56.4, 39.4, 38.6, 34.7, 32.6, 30.7, 22.4, 15.8, 7.7; IR(film): $U_{\max } \mathrm{cm}^{-1} 3414,2935,2812$, 1674, 1458, 1134, 1083; HRMS (ESI, m/z) calcd for $\mathrm{C}_{21} \mathrm{H}_{31} \mathrm{~N}_{2} \mathrm{O}_{3}[\mathrm{M}+\mathrm{H}]^{+}: 359.2329$; found: 359.2324

\section{Synthesis of 9}

Compound 8 on standing in $\mathrm{CDCl}_{3}$ gave compound 9 (1:1 mixture after 2 weeks) which could readily be separated by column chromatography eluting with (30\% EtOAc/Hexanes).

Alternatively, 8 (10 mg, $0.032 \mathrm{mmol})$ was taken up in a $20 \%$ mixture of trifluoroacetic acid in $\mathrm{CDCl}_{3}(0.7 \mathrm{~mL})$. This mixture was then analysed by ${ }^{1} \mathrm{H}$ NMR to confirm complete elimination of EtOH. The mixture was then washed with sat. $\mathrm{K}_{2} \mathrm{CO}_{3}$ solution and the product purified by column chromatography (30\% EtOAc/Hexanes) to give $\mathbf{9}$ as a colourless oil (7 $\mathrm{mg}, 80 \%) ;[\alpha]_{\mathrm{D}}{ }^{20}+7.9\left(\mathrm{c} 0.29, \mathrm{CHCl}_{3}\right) ;{ }^{1} \mathrm{H} \mathrm{NMR}\left(500 \mathrm{MHz}, \mathrm{CDCl}_{3}\right) \delta 7.63(\mathrm{~d}, J=7.8 \mathrm{~Hz}$, 1H), $7.43-7.36(\mathrm{~m}, 1 \mathrm{H}), 7.32(\mathrm{q}, J=3.0,2.0 \mathrm{~Hz}, 2 \mathrm{H}), 6.07(\mathrm{~d}, J=7.7 \mathrm{~Hz}, 1 \mathrm{H}), 5.56(\mathrm{~d}, J=$ $6.3 \mathrm{~Hz}, 1 \mathrm{H}), 4.79(\mathrm{dd}, J=7.8,1.9 \mathrm{~Hz}, 1 \mathrm{H}), 2.81(\mathrm{~d}, J=11.2 \mathrm{~Hz}, 1 \mathrm{H}), 2.67(\mathrm{~d}, J=1.9 \mathrm{~Hz}$, $1 \mathrm{H}), 2.60(\mathrm{t}, J=6.7 \mathrm{~Hz}, 2 \mathrm{H}), 2.24(\mathrm{td}, J=11.7,2.8 \mathrm{~Hz}, 1 \mathrm{H}), 1.92(\mathrm{q}, J=6.2 \mathrm{~Hz}, 2 \mathrm{H}), 1.81$ $(\mathrm{dd}, J=11.9,7.5 \mathrm{~Hz}, 2 \mathrm{H}), 1.60(\mathrm{dt}, J=10.3,2.7 \mathrm{~Hz}, 1 \mathrm{H}), 1.48(\mathrm{dq}, J=14.7,7.5 \mathrm{~Hz}, 1 \mathrm{H})$, $1.26(\mathrm{dq}, J=14.8,7.5 \mathrm{~Hz}, 1 \mathrm{H}), 1.16(\mathrm{td}, J=13.8,4.1 \mathrm{~Hz}, 1 \mathrm{H}), 0.92(\mathrm{t}, J=7.5 \mathrm{~Hz}, 3 \mathrm{H}) .{ }^{13} \mathrm{C}$ NMR $\left(126 \mathrm{MHz}, \mathrm{CDCl}_{3}\right) \delta 175.4,144.9,138.0,129.7,129.1,129.1,127.7,125.7,111.4$, 72.0, 66.8, 53.4, 52.0, 40.7, 39.2, 31.9, 31.3, 23.3, 7.9; IR(film): $v_{\max } \mathrm{cm}^{-1} 3402,2935,2850$, 2812, 1682, 1458, 1130; HRMS (ESI, m/z) calcd for $\mathrm{C}_{19} \mathrm{H}_{25} \mathrm{~N}_{2} \mathrm{O}_{2}[\mathrm{M}+\mathrm{H}]^{+}$: 313.1911; found: 313.1909.

\section{NMR Sample Preparation}

For isotropic measurements a sample of $\sim 20 \mathrm{mg}$ of Melohenine 1, 2 or 3 in $700 \mu l$ of $\mathrm{CDCl}_{3}$ was prepared. For anisotropic measurements the sample was transferred in to a new NMR tube with $89 \mathrm{mg}$ of PBLG $\left(\mathrm{Mw}=1.5-3.5 \times 10^{5}\right.$ g.mol ${ }^{-1}-$ Sigma $)$. After $\sim 12$ hours the sample was centrifuge to achieve homogeneity. Then to provide the lock signal a capillary with DMSO-d6 was added. The homogeneity and stability of the LC phase was monitored by 
${ }^{2} \mathrm{H}$ NMR spectra before and after each anisotropic measurement. The quadrupolar splitting of the solvent signal was 228,247 and $248 \mathrm{~Hz}( \pm 2 \mathrm{~Hz}$ ) for $\mathbf{1}, \mathbf{2}$ and $\mathbf{3}$, respectively (Figure S10).

\section{NMR Measurements}

All NMR spectra we recorded at $295 \mathrm{~K}$ using a Bruker AVANCE III 500 spectrometer equipped with a room temperature $5 \mathrm{~mm}$ BBFO+ probe head. ${ }^{1} \mathrm{H},{ }^{13} \mathrm{C}-\mathrm{CLIP}-\mathrm{HSQC}$ spectra ${ }^{[16]}$ were acquired using 8192 data points over a spectral width of $12 \mathrm{ppm}$ with zero filling by factor of 4 in the ${ }^{1} \mathrm{H}$ dimension; 1024 data points over a spectral width of $180 \mathrm{ppm}$ with $25 \%$ Non Uniform Sampling (NUS) in ${ }^{13} \mathrm{C}$ dimension; 8 scans and a delay of 1s between scans. For ${ }^{1} \mathrm{H},{ }^{13} \mathrm{C}-\mathrm{G}-\mathrm{BIRD}$-HSQC experiment ${ }^{[17]} 1024$ data points over a spectral width of $12 \mathrm{ppm}$ in the ${ }^{1} \mathrm{H}$ dimension; 4096 data points over a spectral width of $180 \mathrm{ppm}$ with $25 \%$ NUS in the ${ }^{13} \mathrm{C}$ dimension; 8 scans and $1 \mathrm{~s}$ delay between scans was used. No scaling or scaling factor of 8 was used for J-evolution in F1 dimension. If Multiple Quantum J-evolution ${ }^{[22]}$ was employed the G-BIRD-HSQC spectra were recorded with 64 scans. Compressed Sensing (CS) method was used for processing of NUS data. All spectra were apodized by $\pi / 2$ shifted sine squared window function in both dimensions.

\section{Computational Methods}

Conformational flexibility of $\mathbf{1}, \mathbf{2}$ and $\mathbf{3}$ was initially assessed by Monte Carlo MMFF conformational search followed by semi-empirical electronic structure calculation using RM1 method. ${ }^{[12]}$ For each compound four conformers with the lowest relative energy were subjected to DFT geometry optimisation in vacuum at B3LYP/6-31G** level of theory. All calculations were performed using Spartan '08 (Version 1.1.2, Build 131) ${ }^{[25]}$ running on Window 7 computer equipped with a IntelCore 2 Quad processor at $2.67 \mathrm{GHz}$ and $8 \mathrm{~GB}$ of memory. The conformations and their energies did not change significantly when a further optimisation with larger basis set B3LYP/6-311G+** was employed.

\section{Acknowledgements}

We would like to acknowledge the EPSRC for funding and the EPSRC UK National Mass Spectrometry Service Centre at Swansea University.

\section{References}

[1] a) P. Y. S. Lam, Y. Ru, P. K. Jadhav, P. E. Aldrich, G. V. DeLucca, C. J. Eyermann, C.H. Chang, G. Emmett, E. R. Holler, W. F. Daneker, L. Li, P. N. Confalone, R. J. 
McHugh, Q. Han, R. Li, J. A. Markwalder, S. P. Seitz, T. R. Sharpe, L. T. Bacheler, M. M. Rayner, R. M. Klabe, L. Shum, D. L. Winslow, D. M. Kornhauser, D. A. Jackson, S. Erickson-Viitanen, C. N. Hodge, J. Med. Chem. 1996, 39, 3514-3525; b) M. Mandal, Z. Zhu, J. N. Cumming, X. Liu, C. Strickland, R. D. Mazzola, J. P. Caldwell, P. Leach, M. Grzelak, L. Hyde, Q. Zhang, G. Terracina, L. Zhang, X. Chen, R. Kuvelkar, M. E. Kennedy, L. Favreau, K. Cox, P. Orth, A. Buevich, J. Voigt, H. Wang, I. Kazakevich, B. A. McKittrick, W. Greenlee, E. M. Parker, A. W. Stamford, J. Med. Chem. 2012, 55, 9331-9345; c) T. Carlomagno, Nat. Prod. Rep. 2012, 29, 536-554.

[2] a) M. B. Schmid, K. Zeitler, R. M. Gschwind, Chem. Sci. 2011, 2, 1793-1803; b) M. B. Schmid, K. Zeitler, R. M. Gschwind, J. Am. Chem. Soc. 2011, 133, 7065-7074.

[3] A. Schuetz, T. Murakami, N. Takada, J. Junker, M. Hashimoto, C. Griesinger, Angew. Chem. 2008, 120, 2062-2064; Angew. Chem. Int. Ed., 2008, 47, 2032-2034.

[4] E. E. Burnell, C. A. de Lange, Chem. Rev., 1998, 98, 2359-2388 and references therein.

[5] a) R. Lipsitz, N. Tjandra, in Modern Magnetic Resonance (Ed.: G. Webb), Springer Netherlands, 2006, pp. 657-664; b) E. de Alba, N. Tjandra, Prog. Nucl. Reson. Spectrosc. 2002, 40, 175-197; c) J. H. Prestegard, C. M. Bougault, A. I. Kishore, Chem. Rev. 2004, $104,3519-3540$.

[6] a) C. M. Thiele, Eur. J. Org. Chem. 2008, 5673-5685. b) B. Luy, K. Kobzar, H. Kessler, Angew. Chem. Int. Ed. 2004, 43, 1092-1094; c) P. Haberz, J. Farjon, C. Griesinger, Angew. Chem. Int. Ed. 2005, 44, 427-429; d) C. Gayathri, N. V. Tsarevsky, R. R. Gil, Chem. Eur. J., 2010, 16, 3622-3626; C. Merle, G. Kummerlöwe, J. C. Freudenberger, F. Halbach, W. Stöwer, C. L. v. Gostomski, J. Höpfner, T. Beskers, M. Wilhelm, B. Luy, Angew. Chem. Int. Ed., 2013, 52, 10309-10312.

[7] a) G. Kummerlöwe, B. Luy in CHAPTER 4 - Residual Dipolar Couplings for the Configurational and Conformational Analysis of Organic Molecules, Vol. Volume 68 (Ed. A. W. Graham), Academic Press, 2009, pp. 193-232; b) C. M. Thiele, V. Schmidts, B. Böttcher, I. Louzao, R. Berger, A. Maliniak and B. Stevensson, Angew. Chem. Int. Ed. 2009, 48, 6708-6712; c) C. Gayathri, M. C. de la Fuente, B. Luy, R. R. Gil, A. NavarroVazquez, Chem. Commun., 2010, 46, 5879-5881; d) H. Sun, U. M. Reinscheid, E. L. Whitson, E. J. d'Auvergne, C. M. Ireland, A. Navarro-Vázquez, C. Griesinger, J. Am. Chem. Soc. 2011, 133, 14629-14636.

[8] P. Trigo-Mouriño, A. Navarro-Vázquez, J. Ying, R. R. Gil, A. Bax, Angew. Chem. Int. Ed. 2011, 50, 7576-7580.

[9] C. S. Lancefield, L. Zhou, T. Lébl, A. M. Z. Slawin, N. J. Westwood, Org. Lett. 2012, 14, 6166-6169.

[10] P. Trigo-Mourino, R. Sifuentes, A. Navarro-Vazquez, C. Gayathri, H. Maruenda, R. R. Gil, Nat. Prod. Commun. 2012, 7, 735-738.

[11] pp. The reduction of $\mathbf{1}$ was complicated by the reactive $\mathrm{C} 14-\mathrm{OH}$ substituent and so isn't discussed in this work.

[12] G. B. Rocha, R. O. Freire, A. M. Simas, J. J. P. Stewart, J. Comput. Chem. 2006, 27, 1101-1111. 
[13] The methylene protons 9-membered rings (H5',H5',,H6',H6'”) in Melohenines show only geminal or vicinal NOE's therefore we could not assign their stereochemistry. As we did not know whether they are on the upper or the lower face of the molecule we could not use vicinal couplings to draw conclusions about the conformation of these rings.

[14]R. R. Gil, Angew. Chem. Int. Ed. 2011, 50, 7222-7224.

[15] A. Marx, C. Thiele, Chem. Eur. J. 2009, 15, 254-260.

[16] A. Enthart, J. C. Freudenberger, J. Furrer, H. Kessler, B. Luy, J. Magn. Reson. 2008, $192,314-322$.

[17] K. Fehér, S. Berger, K. E. Kövér, J. Magn. Reson. 2003, 163, 340-346.

[18] a) J. A. Losonczi, M. Andrec, M. W. F. Fischer, J. H. Prestegard, J. Magn. Reson. 1999, 138, 334-342; b) A. Navarro-Vázquez, Magn. Reson. Chem. 2012, 50, S73-S79.

[19] a) P. Trigo-Mouriño, R. Santamaría-Fernández, V. M. Sánchez-Pedregal, A. NavarroVázquez, J. Org. Chem. 2010, 75, 3101-3104; b) P. Trigo-Mouriño, M. C. de la Fuente, R. R. Gil, V. M. Sánchez-Pedregal, A. Navarro-Vázquez, Chem. Eur. J. 2013, 19, 14989-14997.

[20] G. Cornilescu, A. Bax, J. Am. Chem. Soc. 2000, 122, 10143-10154.

[21] K. E. Kövér, K. Fehér, J. Magn. Reson. 2004, 168, 307-313.

[22] M. Erdélyi, E. d'Auvergne, A. Navarro-Vázquez, A. Leonov and C. Griesinger, Chem. Eur. J. 2011, 17, 9368-9376.

[23] J. I. Seeman, J. Chem. Educ. 1986, 63, 42-48.

[24] M. F. Bartlett, W. I. Taylor, J. Am. Chem. Soc. 1960, 82, 5941-5946.

[25] Y. Shao, L. F. Molnar, Y. Jung, J. Kussmann, C. Ochsenfeld, S. T. Brown, A. T. B. Gilbert, L. V. Slipchenko, S. V. Levchenko, D. P. O'Neill, R. A. DiStasio Jr, R. C. Lochan, T. Wang, G. J. O. Beran, N. A. Besley, J. M. Herbert, C. Yeh Lin, T. Van Voorhis, S. Hung Chien, A. Sodt, R. P. Steele, V. A. Rassolov, P. E. Maslen, P. P. Korambath, R. D. Adamson, B. Austin, J. Baker, E. F. C. Byrd, H. Dachsel, R. J. Doerksen, A. Dreuw, B. D. Dunietz, A. D. Dutoi, T. R. Furlani, S. R. Gwaltney, A. Heyden, S. Hirata, C.-P. Hsu, G. Kedziora, R. Z. Khalliulin, P. Klunzinger, A. M. Lee, M. S. Lee, W. Liang, I. Lotan, N. Nair, B. Peters, E. I. Proynov, P. A. Pieniazek, Y. Min Rhee, J. Ritchie, E. Rosta, C. David Sherrill, A. C. Simmonett, J. E. Subotnik, H. Lee Woodcock Iii, W. Zhang, A. T. Bell, A. K. Chakraborty, D. M. Chipman, F. J. Keil, A. Warshel, W. J. Hehre, H. F. Schaefer Iii, J. Kong, A. I. Krylov, P. M. W. Gill, M. HeadGordon, Phys. Chem. Chem. Phys. 2006, 8, 3172-3191. 


\section{Graphical Abstract}

Residual dipolar coupling analysis has been used to determine the solution conformation of 2 natural products and a related analogue. These structures were compared to the X-ray crystal structures and found to be significantly different in some cases. Quantification of conformational populations has been attempted based on RDC analysis. The knowledge of the preferred conformers enabled us to provide a potential rationalisation for the difference in stereochemical outcome exhibited on ketone reduction.

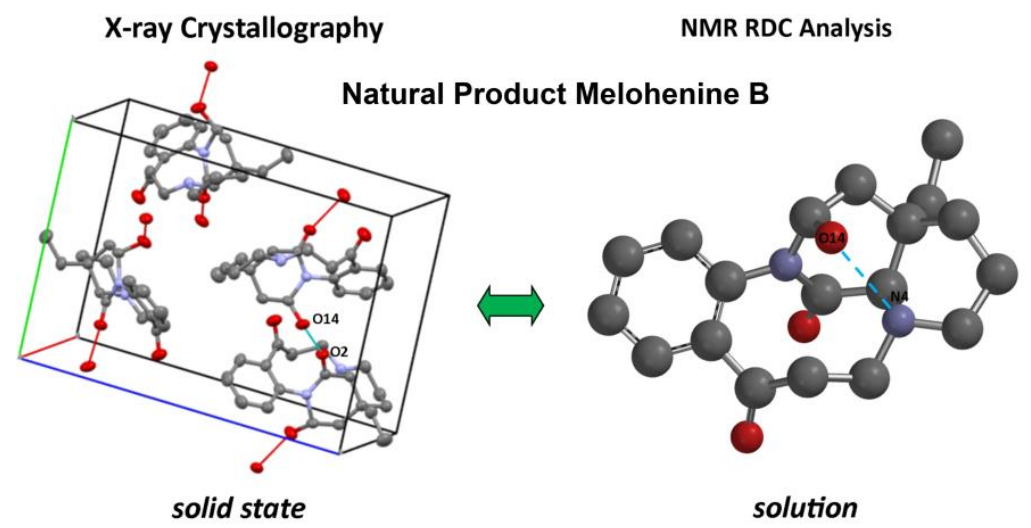


Table 1. Relative enthalpies $\Delta H_{0}(\Delta E+\Delta \mathrm{ZPVE})$ free energies $\Delta G_{298}$ calculated at the B3LYP/6-31G** level of theory in $\mathrm{kJ}^{*} \mathrm{~mol}^{-1}$ and comparison of selected torsion angles $\alpha(\mathrm{O} 2-$ $\mathrm{C} 2-\mathrm{C} 7-\mathrm{O} 7), \beta(\mathrm{C} 2-\mathrm{N} 1-\mathrm{C} 14-\mathrm{C} 15), \gamma(\mathrm{N} 4-\mathrm{C} 3-\mathrm{C} 16-\mathrm{C} 17)$ and $\delta(\mathrm{C} 2-\mathrm{N} 1-\mathrm{C} 14-\mathrm{O} 14)$ in ${ }^{\circ}$ from the structures of 1, 2 and 3 as determined by X-ray crystallography and calculated at the B3LYP/6-31G** level of theory implying that all three molecules prefer to adopt the scc conformation in the solid state.

\begin{tabular}{|ccccccc|}
\hline Entry & $\Delta \mathrm{H}_{0}$ & $\Delta \mathrm{G}_{298}$ & $\alpha$ & $\beta$ & $\gamma$ & $\delta$ \\
\hline $\mathbf{1}$ & - & - & 23.48 & -21.62 & 59.68 & -141.79 \\
$\mathbf{2}$ & - & - & 23.91 & -27.38 & 55.17 & 96.36 \\
$\mathbf{3}$ & - & - & 25.72 & -11.70 & 59.02 & -133.19 \\
\hline 1-scc & 19.88 & 15.09 & 24.61 & -31.43 & 56.54 & -156.1 \\
1-abc & 6.93 & 6.67 & 160.82 & 34.93 & 49.96 & -94 \\
1-sbc & 0 & 0 & 23.87 & 36.04 & 49.99 & -91.8 \\
1-sbb & 10.82 & 9.55 & 24.72 & 37.32 & 28.04 & -89.4 \\
\hline 2-scc & 0.00 & 0.00 & 23.45 & -28.22 & 55.09 & 95.35 \\
2-abc & 8.95 & 7.58 & 167.74 & 38.92 & 52.22 & 155.97 \\
2-sbc & 8.27 & 7.68 & 26.33 & 39.71 & 51.73 & 157.79 \\
2-acc & 13.06 & 11.67 & -166.76 & -31.66 & 56.55 & 90.04 \\
\hline 3-scc & 0.00 & 0.00 & 25.77 & -20.30 & 57.60 & -141.76 \\
3-sbb & 19.39 & 22.89 & 24.25 & 27.42 & 18.96 & -98.73 \\
3-acc & 18.47 & 28.64 & 167.96 & -39.06 & 56.80 & -166.97 \\
3-scb & 21.91 & 23.18 & 25.24 & -26.26 & 46.45 & -146.61 \\
\hline
\end{tabular}


Table 2. The parameters from the RDC analysis (quality factors $Q$, mean quality factors $\langle Q\rangle$, corresponding condition numbers (c.n.) and standard deviations (s.d.), populations of conformers obtained by the single-tensor approximation fitting and corresponding quality factors $Q_{\mathrm{C}}$ ).

\begin{tabular}{|c|c|c|c|c|}
\hline & $\underset{[\mathrm{c} . n .]^{[\mathrm{a}]}}{\mathrm{Q}}$ & $\begin{array}{c}\langle\mathrm{Q}\rangle \\
\text { [s.d.] }\end{array}$ & Populations & $\mathrm{Q}_{\mathrm{C}}$ \\
\hline 1-scc & $\begin{array}{c}0.174 \\
{[5.6]}\end{array}$ & $\begin{array}{c}0.184 \\
{[0.009]}\end{array}$ & 0.00 & \multirow{4}{*}{0.017} \\
\hline 1-abc & $\begin{array}{c}0.035 \\
{[4.6]}\end{array}$ & $\begin{array}{c}0.066 \\
{[0.016]}\end{array}$ & 0.00 & \\
\hline 1-sbc & $\begin{array}{c}0.017 \\
{[18.6]}\end{array}$ & $\begin{array}{c}0.059 \\
{[0.018]}\end{array}$ & 1.00 & \\
\hline 1-sbb & $\begin{array}{c}0.049 \\
{[9.5]}\end{array}$ & $\begin{array}{c}0.074 \\
{[0.014]}\end{array}$ & 0.00 & \\
\hline 2-scc & $\begin{array}{l}0.059 \\
{[4.0]}\end{array}$ & $\begin{array}{c}0.074 \\
{[0.009]}\end{array}$ & 0.53 & \multirow{4}{*}{0.038} \\
\hline 2-abc & $\begin{array}{c}0.448 \\
{[5.7]}\end{array}$ & $\begin{array}{c}0.450 \\
{[0.006]}\end{array}$ & 0.00 & \\
\hline 2-sbc & $\begin{array}{l}0.192 \\
{[3.8]}\end{array}$ & $\begin{array}{c}0.197 \\
{[0.004]}\end{array}$ & 0.30 & \\
\hline 2-acc & $\begin{array}{l}0.436 \\
{[12.4]}\end{array}$ & $\begin{array}{c}0.438 \\
{[0.004]}\end{array}$ & 0.17 & \\
\hline 3-scc & $\begin{array}{l}0.067 \\
{[6.2]}\end{array}$ & $\begin{array}{c}0.092 \\
{[0.015]}\end{array}$ & 0.80 & \multirow{4}{*}{0.051} \\
\hline 3-sbb & $\begin{array}{l}0.178 \\
{[7.0]}\end{array}$ & $\begin{array}{c}0.189 \\
{[0.008]}\end{array}$ & 0.00 & \\
\hline 3-acc & $\begin{array}{c}0.367 \\
{[6.6]}\end{array}$ & $\begin{array}{c}0.373 \\
{[0.008]}\end{array}$ & 0.00 & \\
\hline 3-scb & $\begin{array}{c}0.254 \\
{[5.8]}\end{array}$ & $\begin{array}{c}0.262 \\
{[0.008]}\end{array}$ & 0.20 & \\
\hline
\end{tabular}

[a] Condition number shows robustness of the SVD fit. Values above 30 are generally accepted as indicating lack of proper spanning of alignment tensor space. 
Table 3. Model selection based on the AIC

\begin{tabular}{|llll|}
\hline Model & Populations & Q & AIC \\
\hline 2-scc & 1.00 & 0.059 & 34.2 \\
2-scc + 2-sbc & $0.83: 0.17$ & 0.047 & 28.3 \\
2-scc + 2-sbc + 2-acc & $0.53: 0.30: 0.17$ & 0.038 & 25.3 \\
\hline 3-scc & 1.00 & 0.067 & 108.2 \\
3-scc + 3-scb & $0.80: 0.20$ & 0.051 & 126.5 \\
\hline
\end{tabular}

